\title{
Clickers in the Laboratory: Student Thoughts and Views
}

\author{
Kevin Johnson and Catherine Lillis \\ University of Limerick, Limerick, Ireland
}

\author{
kevin.johnson@ul.ie; Catherine.Lillis@ul.ie
}

\begin{abstract}
Many methods are used to enhance student engagement in instructional nursing education courses, and systems are introduced as new technologies become available. The aim of this research was to evaluate student's experiences of the use of an Audience Response System (ARS) aka Clickers - in the laboratory setting and determine if it improved student knowledge retention and contributed to the body of research in this area. Students used handheld RF devices to respond to PowerPoint questions in relation to wound care and management. This approach helped to focus student's attention and provide feedback on student's comprehension of material. Use of ARS devices facilitated preparation for an in-class Moodle quiz. Focused ARS questions helped students maintain attention and stay motivated to learn. Feedback allowed clinical skills facilitators to adapt laboratory sessions to address areas of deficiency.
\end{abstract}

Keywords: Audience, Response, System, Technology, and Learning.

\section{Introduction}

This paper presents the perceptions of Irish Nursing students with regard to the use of technology in the clinical skills laboratories. Many instructors at both large and small educational institutions have begun to use classroom technology that allows students to respond and interact via small, hand-held, remote keypads called "Clickers". It resembles the "Ask the Audience" portion of the game show "Who Wants to be A Millionaire" and enables instructors to instantaneously collect student responses to a posted question, generally multiple choice. The answers are immediately tallied and displayed on a classroom projection screen where both students and instructor can see and discuss them. This technology is known under many names and will be referred to as an audience response system (AR system or ARS). Audience Response Systems are an evolving inclass student-polling technology designed to create an engaging and inviting learning environment that maximizes active learning. Unfortunately, there appears to be no standardization of terminology in the literature; audience response systems are variously described by vendors and academic users as: audience-paced feedback systems (APF), student response systems (SRS),

Material published as part of this publication, either on-line or in print, is copyrighted by the Informing Science Institute. Permission to make digital or paper copy of part or all of these works for personal or classroom use is granted without fee provided that the copies are not made or distributed for profit or commercial advantage AND that copies 1) bear this notice in full and 2) give the full citation on the first page. It is permissible to abstract these works so long as credit is given. To copy in all other cases or to republish or to post on a server or to redistribute to lists requires specific permission and payment of a fee. Contact Publisher@InformingScience.org to request redistribution permission. classroom performance systems (CPS), electronic response systems (ERS), hyper-active teaching technology (H-ITT), interactive engagement (IE), interactive audience response systems (IRIS), interactive learning systems (ILS), interactive student-response systems (ISRS), personal response systems (PRS), group response systems (GRS), and wireless response systems (WRS). For the purpose of this research, the ARS acronym 
will be used to refer to this technology. This is a relatively new technology that offers easy deployment of active learning and engagement within any learning environment.

One of the aims of the research was to evaluate students' experiences of the use of technology in supporting their learning styles. Another objective was to determine if the students better retained the knowledge of the module with the user of the ARS or Clicker technology. This was achieved via an online quiz in Moodle in the penultimate week of the semester. Many methods are used to enhance student engagement in instructional nursing education courses (Moredich \& Moore, 2007; Richardson \& Trudeau, 2003) and systems are introduced as new technologies become available (Fink, 2005; Fitch, 2004; Roberts, 2005; Skiba \& Barton, 2006; Weimer, 2002).

The operation of an ARS is a simple three-step process:

1) During the teaching period, the instructor displays or verbalizes a question or problem, previously prepared or spontaneously generated "on the fly" by the instructor or a student,

2) All students key in their answers using wireless handheld keypads - aka "Clickers",

3) Responses are received, aggregated, and displayed on both the instructor's computer monitor and an overhead projector screen. The distribution of student responses may prompt the students or instructor to further explore the key area with discussion or, perhaps, one or more follow-up questions.

This interactive cycle can continue until both the instructor and the students have resolved ambiguities or reached closure on the topic at hand (Lowery, 2006).

\section{Background}

The B.Sc Nursing (General, Mental Health, and Intellectual Disability) is a full-time four year programme offered by the Department of Nursing and Midwifery, Faculty of Education and Health Sciences, University of Limerick in conjunction with the Health Services Executive MidWest (Limerick, Clare, and North Tipperary). Upon successful completion of the programme students will register with An Board Altranais (ABA) and practice as a Registered Nurse (R.G.N), Registered Psychiatric Nurse (R.P.N.) or Registered Nurse Intellectual Disability (R.N.I.D). The curriculum encompasses the development of theory and practice simultaneously and includes lectures, clinical skills laboratory work, tutorials, and clinical placement.

The undergraduate Bachelors of Science in Nursing at the University of Limerick has a significant clinical skills component embedded into the modular structure and taught to students in conjunction with relevant theory. Content covered in Clinical Skills Laboratories is a component of the module and is subject to assessment and examination. The focus of this research is on wound care assessment and management. Participants were $2^{\text {nd }}$ Year Students from the Module NS3201 - Microbiology Immunology and Infection Control. Students who participated were from disciplines in general nursing, mental health and intellectual disabilities. See Table 1 for the percentage breakdown on the students.

Table 1: Breakdown of Student Numbers

\begin{tabular}{|l|l|l|r|}
\hline \multicolumn{1}{|c|}{ Disciplines } & \multicolumn{1}{c|}{ Group } & \multicolumn{1}{c|}{ Total } & \multicolumn{1}{c|}{ N } \\
\hline Mental Health & 1 & $30.6 \%$ & 13 \\
\hline Intellectual Disability & 2 & $26.5 \%$ & 21 \\
\hline General Nursing & 3 & $42.8 \%$ & 49 \\
\hline & Total & $100 \%$ & 15 \\
\hline
\end{tabular}


Lectures were two hours a week, eight lectures in total, in which the students focused on the theory applications of the module. The theory was complimented via an online lectures module delivered with the Universities Content Management System - "Sulis". This is a branded version of the Sakai system (Risquez, 2006).

The staff of the Nursing and Midwifery Department facilitated the laboratory session. This involved a two-hour clinical skills session in which the students practiced what they learned. The lecturer facilitated discussion in relation to description of various types of wounds. The physiology of wound healing, the criteria for wound dressing, and choosing the appropriate dressing for each type of wound were all investigated.

The information for the laboratory sessions was made available online - on another Content Management System called Moodle. Moodle offered better resource deployment capability over Sulis and was therefore used by the lab facilitator. Here the students had access to several online resources in the form of PowerPoint slides, additional reading in pdf documents, and video clips ranging from 5-10 minutes in duration. The clips focused on the areas of interest to the students for the module. The students were made aware of these resources and told to watch the videos in their own free time.

The lab facilitator had three different groups for the given module: one on Monday afternoon hereafter referred to as Group 1; one Thursday morning, hereafter referred to as Group 2; and the final session Thursday at midday, hereafter referred to as Group 3. Each group ranged in size from 13 students in Group 1 to 21 students in Group 3.

The introduction of the Clickers into the laboratory environment was a pilot phase to gauge students' thoughts on their appropriateness and also to decipher if they aided students in studying for in class assessments. This was achieved in the penultimate week of teaching in the University when the students had a supervised online quiz in the Moodle environment. The department purchased $160 \mathrm{RF}$ handsets for approximately 12,000 USD or 8,000 euro. The software for creating the interactive slides is freely available online at http://www.turningtechnologies.com/. This software installs on a Windows or Mac computer with MS Office 2003. A new toolbar is available to the user to create the interactive slides upon restart of the system. The teaching and delivery of the Clickers was as follows:

Group 1 - received access to Moodle in Week 9. In week 10, the students had a clicker based quiz in which the results were reviewed at the end of the two-hour teaching period. The session was not graded and participation was voluntary and the data collected was anonymously submitted. The following week the online quiz took place.

Group 2 - received access to Moodle in Week 9. In week 10, the students had a clicker based quiz in which the results were reviewed at the end of each question in the two-hour teaching period. The session was not graded, participation was voluntary and the data collected was anonymously submitted. The following week the online quiz took place.

Group 3 - received access to Moodle in Week 9. In week 11, the students had a clicker based quiz in which the results were reviewed at the end of each question. The session was not graded, participation was voluntary and the data collected was anonymously submitted. Following this, the online quiz took place.

The module NS3201 Microbiology Immunology \& Infection Control was taught during the first semester of the second year and focused on hand hygiene, infectious diseases, specimen collection, aseptic technique, wound care, wound management, and suture removal. It is offered every year, in the autumn, with approximately 120 students registering to take the module. Historically, it has been difficult to solicit student engagement, with the majority of the students refusing to initiate verbal discussion or start meaningful discourse amongst the other students in the lab. 
Faculty noted that students often failed to attend lecture and laboratory sessions. Lack of engagement and understanding was evident in the laboratory sessions. The students found simple questions on topics from the previous week difficult to answer, even though they thought they were familiar with the information. Clickers were proposed as a way to enhance and actively engage student understanding of the information through immediate feedback, allowing the lab facilitator to determine if clarification of content was needed. An online quiz was developed by the lab facilitator to take place in the penultimate week of the semester. This would account for a percentage mark of their overall grade in the module. It was also an underpinning aim of this research to evaluate if use of the Clickers to actively engage the students in the laboratory session was beneficial to their retention of the knowledge being taught at the time.

\section{Literature Review}

Currently, students have a preference for digital literacy, experiential learning, interactivity, and immediacy (Howe \& Strauss, 2000; Skiba \& Barton, 2006). Greater use of technology has been introduced into classrooms to encourage student involvement (Johnson \& McLeod, 2005; Moredich \& Moore, 2007; Ribbens, 2007) in the past several years. Research has shown that actively engaged students will absorb and retain more content (Moredich \& Moore, 2007; Trotter, 2005). It has also been shown that using a variety of teaching/learning methodologies enhances learning for students with differing learning styles (Barell, 2003; Fink, 2005). A learner-centered teaching approach (Weimer, 2002) and the creation of significant learning experiences (Barell, 2003; Fink, 2005) are touted as means of creating interaction in the classroom.

Clickers, an emerging technology, have been used to actively engage students within a learning environment, be it lecture theatre, tutorial room, or laboratory setting, and provide immediate feedback regarding their understanding of the learning material. Content students do not comprehend is identified so that complicated material may be clarified (Hatch, Jensen, \& Moore, 2005; Howe \& Strauss, 2000; Moredich \& Moore, 2007; Stein, Challman, \& Brueckner, 2006; Trotter, 2005). Research has supported that Clickers create an atmosphere of student interaction that enhances critical thinking and the ability to utilize knowledge in the safety of the learning environment. Students come to learn better prepared as they know there will be a quiz, and Clickers support stimulating discussion among students about the plausibility of quiz responses (Fitch, 2004; Hatch, et al., 2005; Johnson \& McLeod, 2005; Moredich \& Moore, 2007; Ribbens, 2007; Skiba \& Barton, 2006; Trotter, 2005).

The handheld devices used in an ARS - commonly called "Clickers" or "key-pads" in the United States and "handsets" or "zappers" in the United Kingdom (d'Inverno, Davis, \& White, 2003; Ribbens, 2007; Simpson \& Oliver, 2007) - are small transmitters approximately the size of a credit card. Students use their Clickers to transmit their answers by pressing the appropriate buttons. Although one early example of a clicker had a single response button (Poulis, Massen, Robens, \& Gilbert, 1998), modern Clickers usually have a 10-digit numeric keypad and often some accessory buttons including a power switch, a send button, or function keys that permit text entry (Barber \& Njus, 2007).

Modern clicker units are "two-way," meaning that the clicker not only sends a signal but also indicates whether it was received. Although early Clickers were often connected to the rest of the system by wiring, modern systems are wireless and use either infrared (IR) or, more recently, radio frequency $(\mathrm{RF})$ signals. The RF systems are rapidly becoming the current standard because they send stronger signals, require only a single receiver, do not experience interference from classroom lights or other IR-emitting equipment, and do not require a direct line of sight between the student and the receiver. In all AR systems, each clicker unit has a unique signal so that the answer from each individual student can be identified and recorded. When polling is complete, answers from the entire class are displayed on the projection screen, usually in the form of a his- 
togram, although some systems offer more sophisticated options (Roschelle, Penuel, \& Abrahamson, 2004). The feature of an ARS that allows this incoming mass of student answers to be rapidly collected, tabulated and displayed is the coupling of a proprietary receiver unit with an ordinary classroom computer and projection system. Figure 1 displays a graphic representation of how Clickers might be used in a learning environment.

\section{Classroom Response Systems: Technical Components and Interactions}

\section{Instruction \& Questioning}

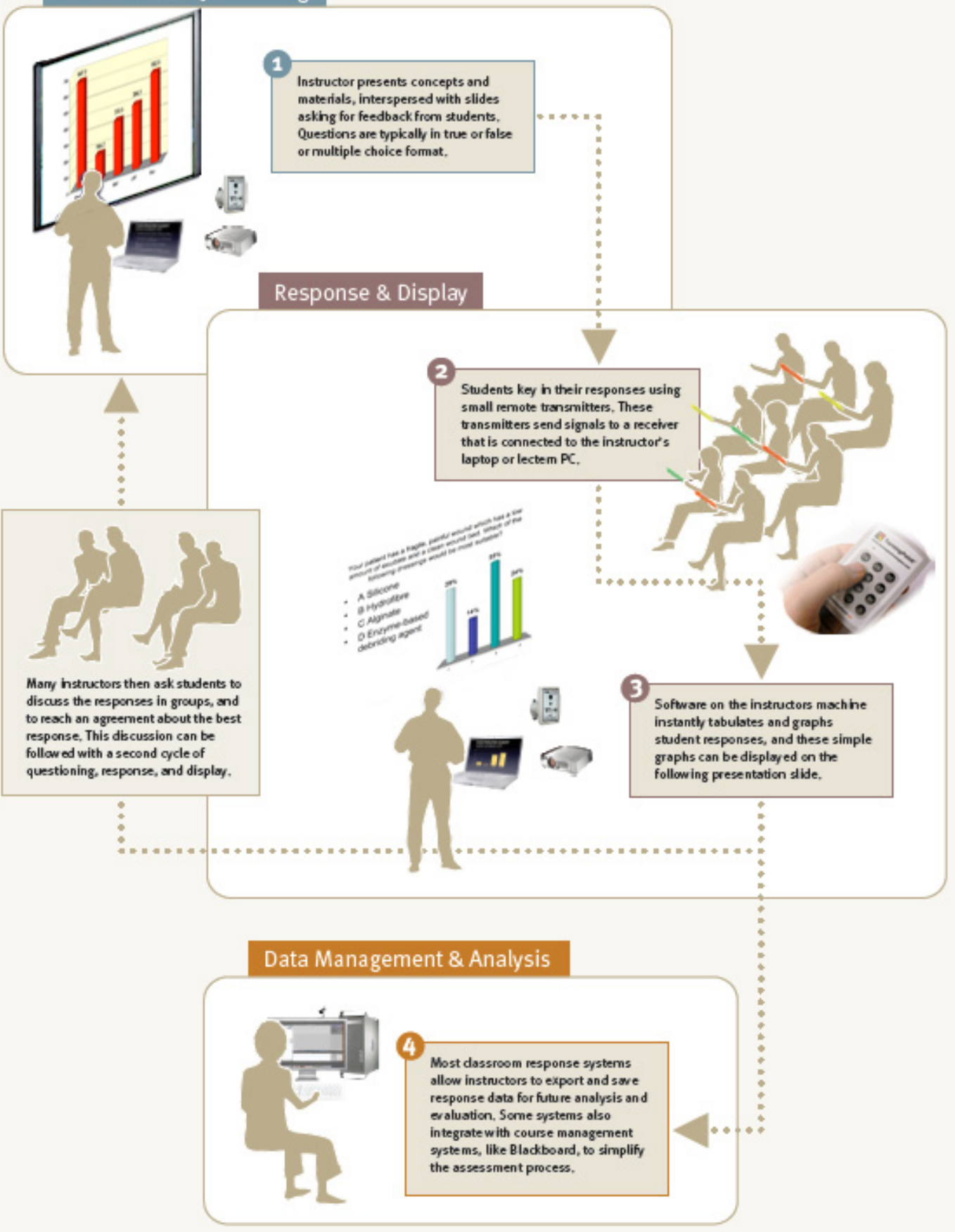

Figure 1: How the Clickers Work 
ARS technology has been successfully used in varied course formats, ranging from optional tutorials (d'Inverno et al., 2003) to formal standard lectures and cooperative learning through peer instruction (Nicol \& Boyle, 2003).

\section{Research Aims}

The aims of this research were to:

- Evaluate students experiences of the use of Clickers in the laboratory setting

- Determine if the Clickers improved a students knowledge retention via an online quiz over a two year period

- Determine if the Clickers actively engage the students in the laboratory session

- Contribute to the body of research in this area to enhance discipline specific curriculum resources.

\section{Research Methodology}

This study evaluated outcomes relating to student attainment of knowledge and practice with regard to the Nursing module. The students were assigned to groups by the Student Service department within the University. The groups were allocated a given day and time that their laboratory session would take place. This session ran from week 1 to week 12 of the academic semester.

In the first four weeks of the semester, week 1 to week 4, the students focused on hand hygiene, standard precautions, infectious diseases, and specimen collection. This section was delivered via the standard means of delivery. The students attended the laboratory session and the facilitator taught the material under review. Content was delivered via PowerPoint presentation, DVD's, handouts, article reviews, group work, and case studies. The students had the opportunity to ask questions or engage in discussions with the facilitator, but active discussion rarely occurred. The students did have an opportunity to fill in an evaluation form at the end of each laboratory session voicing their thoughts and feelings with regards to the content they were studying and their understanding of the content.

The middle four-week period, week 5 to week 8, the students were out on placement. This means that they were not physically on campus and therefore not available for lectures or laboratory sessions. The Allocations Office undertook the placement allocation. Upon completion of placement and after returning to the University, the students were welcomed back to a different scenario.

The final four-week section of the semester, week 9 to week 12, focused on aseptic technique, suture removal, wound assessment, and wound management. The content for the laboratory session was made available to the students online via a content management system called Moodle. The students could access this system from on and off campus locations. Material in the form of PowerPoint slides, additional reading in PDF format, Policy documents, and video clips in web based flash format was made available to the students on a week-by-week basis. The same material was taught in the laboratory sessions.

The students were introduced to the concept of the Clicker technology for wound care and management. Two groups - Group 1 and Group 2 - availed of this feature in the week 10 laboratory session. The other group - Group 3 - used the Clicker technology in week 11 - directly before the in-class Moodle quiz. 


\section{Results}

The overall scores of the three groups are shown in Table 2. Additional information includes the average score of the test per group, the shortest and longest time and accompanying score with each, and finally the lowest and highest score per quiz per group. The quiz repository was designed with 30 questions based in the area of wound care and management. Each quiz was comprised of 20 randomly selected questions and displayed for the students at a specific time of the week. They had 10 minutes to complete the test and submit their work online. The overall grade was out of 10 .

Table 2: Overall Results for Moodle Quiz

\begin{tabular}{|l|l|l|l|l|r|r|}
\hline Group & N & Avg Score & Shortest Time & Longest Time & Low Score & High Score \\
\hline 1 & 12 & 7.67 & $4 \mathrm{~m} \mathrm{32s} \mathrm{(6)}$ & $9 \mathrm{~m} \mathrm{03s} \mathrm{(7.5)}$ & 6 & 9 \\
\hline 2 & 10 & 7.45 & $5 \mathrm{~m} \mathrm{47s} \mathrm{(6.5)}$ & $10 \mathrm{~m} 03 \mathrm{~s}(9)$ & 6.5 & 9 \\
\hline 3 & 21 & 8.07 & $3 \mathrm{~m} \mathrm{32s} \mathrm{(7.5)}$ & $10 \mathrm{~m} \mathrm{00s} \mathrm{(8)}$ & 6.5 & 9.5 \\
\hline
\end{tabular}

The students of all three groups attended the laboratory sessions and were informed of the interactive session with the Clickers.

Your patient has a fragile, painful wound which has a low amount of exudate and a clean wound bed. Which of the following dressings would be most suitable?

- A Silicone

- B Hydrofibre

- C Alginate

- D Enzyme-based debriding agent

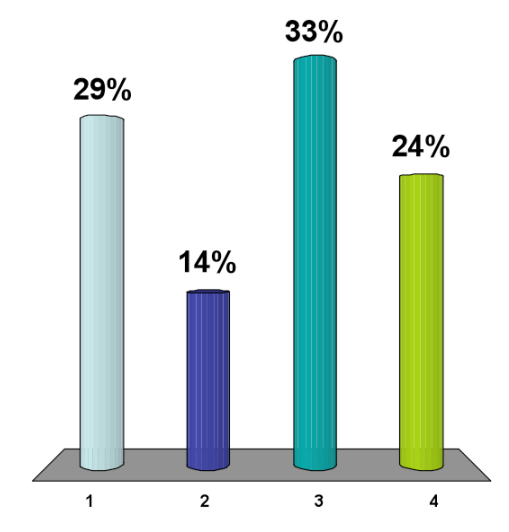

Figure 2: Sample PowerPoint Presentation Question

A PowerPoint presentation was prepared in which approximately 50 questions on wound care and wound management were created. The questions were randomly generated based on the material that was taught to the students in the laboratory sessions. The format of the questions was a variety of True/False, Yes/No, or multiple choice type answers. Interactive slides take no longer to create than a standard PowerPoint slide. A sample question is shown in Figure 2.

The lab facilitator set up the presentation of the questions halfway through the lab session. The first one-hour of the lab was used to cover material relating to the topic of study. The format of this material was web based video files and other PowerPoint presentations. The students studied this material and asked any questions pertaining to it. This structure was used to teach Group1 and Group 2 students. Group 3 students studied the material at home or in their free time. They used the Clickers on the morning of the online quiz. 
Figures 3-5 show the anonymous responses submitted by the students for a question that was categorized as easy by the facilitator. The TurningPoint software installed on the computer allowed the facilitator to save each session as it occurred. In this way, the information from each session was safely backed up and saved on the computer and a new empty session could commence when the next lab group entered the facilities. Figure 3 relates to the response from Group 1, Figure 4 from Group 2 and Figure 5 from Group 3.

\begin{tabular}{lrr} 
11.) The most commonly used cleaning agent is? & Responses \\
\hline \hline A Sterile normal saline (0.9\%) & 13 & $100 \%$ \\
B Hydrogen Peroxide & 0 & $0 \%$ \\
C Povidone-iodine solution & 0 & $0 \%$ \\
D sodium hypochlorite & 0 & $0 \%$ \\
Totals & 13 & $100 \%$
\end{tabular}

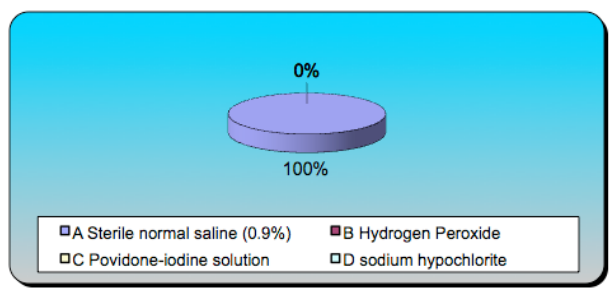

Figure 3: Group 1 Response to an Easy Question

\begin{tabular}{lrr} 
7.) The most commonly used cleaning agent is? & Responses \\
\hline \hline & & \\
A Sterile normal saline (0.9\%) & 14 & $100 \%$ \\
B Hydrogen Peroxide & 0 & $0 \%$ \\
C Povidone-iodine solution & 0 & $0 \%$ \\
D sodium hypochlorite & 0 & $0 \%$ \\
Totals & 14 & $100 \%$
\end{tabular}

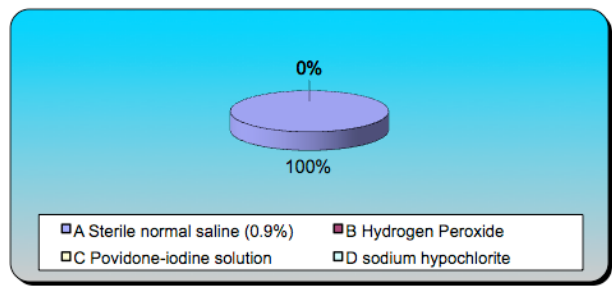

Figure 4: Group 2 Response to an Easy Question

\begin{tabular}{lrr} 
8.) The most commonly used cleaning agent is? & \multicolumn{2}{c}{ Responses } \\
\hline \hline A Sterile normal saline (0.9\%) & 21 & $100 \%$ \\
B Hydrogen Peroxide & 0 & $0 \%$ \\
C Povidone-iodine solution & 0 & $0 \%$ \\
D sodium hypochlorite & 0 & $0 \%$ \\
Totals & 21 & $100 \%$
\end{tabular}

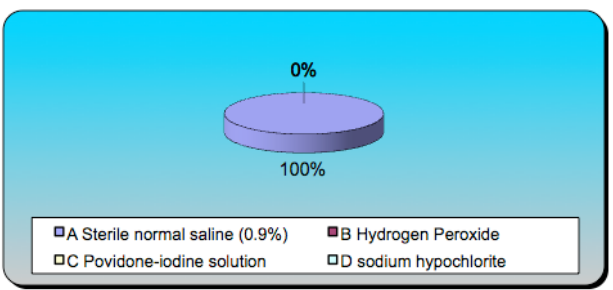

Figure 5: Group 3 Response to an Easy Question

As one can see from the answers submitted by the students, there was no need for discussion with this question. All the students from all the groups got the answer right and the facilitator was ready to move on to the next question. It was agreed between the facilitator and the others carrying out this research to start with easier question to build the confidence of the students. It was noted that this was their first time to use this sort of technology and it was agreed that several easier questions to be begin with was a good way to build up their confidence.

Figures 6-8 relate to the responses received from the students with regard to a harder question. As one can see from the pie chart graphs for each group, there was a mixed set of answers submitted to the facilitator. This, in turn, opened up the floor to questions from the students on what 
was the right answer and why. Some students tend to be more verbal and forthright than others, but the result was the same regardless - all students benefitted from the discussion as to what was the correct answer, and in doing so gained a deeper understanding of the question posed.

\begin{tabular}{l}
$\begin{array}{l}\text { 8.) You smell an unpleasant odour as you remove your } \\
\text { patient's dressing. Which type of dressing may cause } \\
\text { this? }\end{array}$ \\
\hline \hline
\end{tabular}

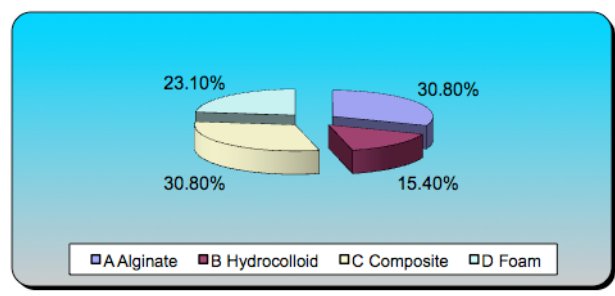

Figure 6: Group 1 Response to a Hard Question

\begin{tabular}{l}
$\begin{array}{l}\text { 4.) You smell an unpleasant odour as you remove your } \\
\text { patient's dressing. Which type of dressing may cause } \\
\text { this? }\end{array}$ \\
\hline \hline
\end{tabular}

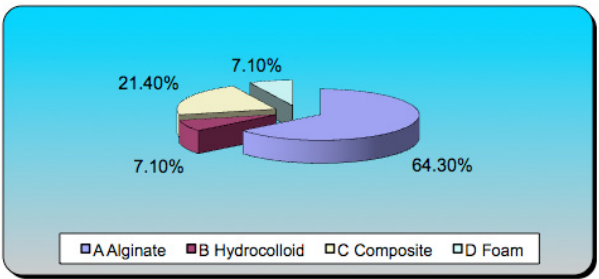

Figure 7: Group 2 Response to a Hard Question
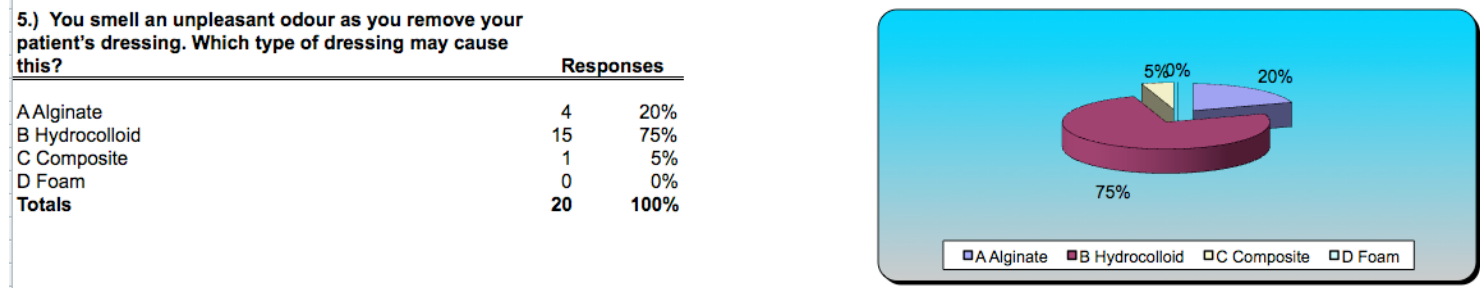

Figure 8: Group 3 Response to a Hard Question

Different methods were used to review the questions with the students.

Group 1, each question was asked and at the end of the lab session, the correct answer was given and discussions would commence. When the students were asked their thoughts on this method, the verbal consent was that it was better to review the questions after asking the question. In this way, the question and thought process was still fresh in the students mind. They were more willing and open to discussion on the top. Towards the end of a two-hour lab session, the students were more focused on getting ready to leave for their next class or heading home for the day.

Group 2 received the answers to the questions after each question was asked. This did raise more discussion amongst the lab facilitator and the students. The students were curious to know the correct answers and interact with the group to find out what the correct answer was and why.

Group 3 also used the method used with Group 2 except that they did it in the first half of the laboratory session and then went straight on to complete the online quiz on Moodle in the second half of the lab session. 
After the quiz on Moodle was completed, the students were asked to fill in an anonymous questionnaire and share with us their thoughts and findings on using the Clicker technology. 40 students had responded at the time of the writing of this paper, but there was still another week of teaching to complete and students had this time to fill in the questionnaire. As one can see from the responses submitted, all students thought that the Clickers were positively contributing towards their understanding of the given topic $(4.5 / 5)$, as well as enhancing their learning $(4.5 / 5)$, involvement (4.5) and interaction (4.5/5) in the laboratory environment. The students would like to see this technology used more in other clinical skills labs $(4.5 / 5)$ and strongly agreed that the use of the Clickers helped in their preparation for the Moodle online quiz in week 11. Full details are available in Figure 9.

9. Please answer the following questions

\begin{tabular}{|c|c|c|c|c|c|}
\hline & \multicolumn{4}{|c|}{ Average rank } & \\
\hline & \begin{tabular}{|l|l|}
$\begin{array}{l}\text { Strongly } \\
\text { Disagree }\end{array}$ & Disagree \\
\end{tabular} & $\mathrm{N} / \mathrm{A}$ & Agree & \begin{tabular}{|l|} 
Strongly \\
Agree
\end{tabular} & \\
\hline $\begin{array}{l}\text { Using the clickers helped me to verify my understanding of } \\
\text { wound care and management }\end{array}$ & & \multicolumn{3}{|c|}{ 】 } & 4.5 \\
\hline Participating with the clickers enhanced my learning & & \multicolumn{3}{|c|}{ I } & 4.5 \\
\hline $\begin{array}{l}\text { Participation with the clickers increased my involvement in the } \\
\text { classroom }\end{array}$ & & \multicolumn{3}{|c|}{ 【 } & 4.5 \\
\hline $\begin{array}{l}\text { Participation with the clickers increased my interaction with the } \\
\text { lab facilitator }\end{array}$ & & \multicolumn{3}{|r|}{ 【 } & 4.5 \\
\hline I would recommend using clickers in clinical skills labs & & \multicolumn{3}{|c|}{ 】 } & 4.5 \\
\hline The clickers helped me stay focused and motivated me to learn & & \multicolumn{3}{|c|}{ I } & 4.5 \\
\hline $\begin{array}{l}\text { The use of the clickers helped in my preperation for the moodle } \\
\text { assessment on wound care and mangagement }\end{array}$ & & \multicolumn{3}{|r|}{ I } & 4.5 \\
\hline The clickers helped me to validate my own learning & & \multicolumn{3}{|c|}{ I } & 4.5 \\
\hline I enjoyed using the clickers & & \multicolumn{3}{|r|}{ I } & 4.6 \\
\hline
\end{tabular}

Figure 9: Student views on using the Clickers

\section{Conclusions}

An audience response system used in the microbiology immunology and infection control module improved student motivation and attention and provided immediate feedback to the instructor concerning student understanding of wound care and management.

Responses on the student questionnaire indicated that the ARS approach helped maintain student attention and provided a positive acceptance of this approach as a way to engage students.

According to student feedback, asking questions via the ARS achieved its goal. Students indicated that this approach helped them learn material more effectively, stay focused, and verify their understanding. Their use enhanced their learning and students enjoyed the experience. A secondary benefit provided feedback to the instructor with regard to student comprehension of material content and increased student interaction with the lab facilitator.

In addition, the use of Clickers helped students in their preparation for the Moodle assessment on wound care and management. The higher grades for group 3 suggest that the use of ARS prior to the Moodle assessment contributed to a positive effect on student grades with a highest average score of 8.07 and the highest score per quiz of 9.5. In addition group 1 and 2 achieved high scores of 9 with an average score ranging from 7.45 to 7.67 respectively. The same content - without the ARS technology - will be delivered next year to another group of $2^{\text {nd }}$ Year students. A comparison of the Moodle quiz results will show if the 2009 or 2010 students retained a better understanding of the module material. 
From the clinical skills facilitators' viewpoint, the ARS helped to clarify points that students misunderstood. If student's answers revealed lack of comprehension on a certain question, the facilitator could address the difficulties immediately through classroom discussion. The ARS provided feedback to both the instructor and students, allowing focused discussion only on those topics that students misunderstood the most. Time for discussion varied based on feedback. Furthermore, class time was not misspent on topics or concepts already understood by more than $90 \%$ of the class. The instructor was pleased with the ARS strategy and its resulting improvements to classroom attention, learning, improved student motivation, participation, and excellence.

There is however some limitations associated with this study. A greater support system needs to be in place to sustain students and staff with the new influx of technology in their learning environment. This study focused on students as the key stakeholders. Further research is required into the contribution of these technologies to the acquisition of skills in the Clinical Skills Laboratory environment and to ascertain the views of academic staff. Although the process explored focused on a Nursing Clinical Skills environment, it is relevant to many disciplines and can be tailored to suit their diverse and varying needs. Embracing changes that may improve the teaching and learning process help maximize the benefits enjoyed by all.

The study documented the successes of using Clickers to increase student attention and provide the facilitator with feedback. The study provides further information on student thoughts and views with using ARS as proposed by (Fies \& Marshall, 2006; Kennedy \& Cutts, 2005; Medina, Medina, Wanzer, Wilson, Er, \& Britton, 2008; Trapskin, Smith, Armitstead, \& Davis, 2006). Positive feedback about using ARS in the microbiology Immunology and Infection control encouraged the authors to integrate this approach into the other sections of the module. Overall, this has been a valuable innovation for the module, and we will continue to use, evaluate and improve upon this approach in the future.

Further studies are warranted to establish the direct and indirect effects of the ARS approach on student grades and facilitator evaluations.

\section{References}

Barber, M., \& Njus, D. (2007). Clicker evolution: Seeking intelligent design. CBE Life Science Education, $6,1-20$.

Barell, J. (2003). Developing more curious minds. Association for Supervision \& Curriculum Development.

d'Inverno, R. A., Davis, H. C., \& White, S. (2003). Using a personal response system for promoting student interaction. Teaching Mathematics Applications, 22(4), 163-169.

Fies, C., \& Marshall, C. (2006). Classroom response systems: A review of the literature. Journal of Science Education and Technology, 15(1), 101-109.

Fink, L. D. (2005). Creating significant learning experiences: An integrated approach to designing college courses. Journal of Chemical Education, 82(6), 819-819.

Fitch, J. (2004). Student feedback in the college classroom: A technology solution. Educational Technology Research and Development, 52(1), 71-77.

Hatch, J., Jensen, M., \& Moore, R. (2005). Manna from heaven or "clickers" from hell: Experiences with an electronic response system. Journal of College Science Teaching, 34(7), 36-42.

Howe, N., \& Strauss, W. (2000). Millennials rising: The next great generation. New York: Vintage Books.

Johnson, D., \& McLeod, S. (2005). Get answers: Using student response systems to see students' thinking. Learning and Leading with Technology, 32(4), 18-23. 
Kennedy, G., \& Cutts, Q. (2005). The association between students' use of an electronic voting system and their learning outcomes. Journal of Computer Assisted Learning, 21(4), 260-268.

Lowery, R. (2006). Clickers in the classroom: A comparison of interactive student-response keypad systems. Paper presented at the The National Technology and Social Science Conference.

Medina, M. S., Medina, P. J., Wanzer, D. S., Wilson, J.E., Er, N., \& Britton, M.L. (2008). Use of an audience response system (ARS) in a dual-campus classroom environment. American Journal of Pharmaceutical Education, 72(Article 38).

Moredich, C., \& Moore, E. (2007). Engaging students through the use of classroom response systems. Nurse Educator, 32(3), 113-116.

Nicol, D. J., \& Boyle, J. T. (2003). Peer instruction versus class-wide discussion in large classes: A comparison of two interaction methods in the wired classroom. Studies in Higher Education, 28(4), $457-473$.

Poulis, J., Massen, C., Robens, E., \& Gilbert, M. (1998). Physics lecturing with audience paced feedback. American Journal of Physics, 66(5), 439-441.

Ribbens, E. (2007). Why I like personal response systems. Journal of College Science Teaching, 37(2), 6062.

Richardson, K., \& Trudeau, K. J. (2003). A case for problem-based collaborative learning in the nursing classroom. Nurse Educator, 28(2), 83-88.

Risquez, A. (2006). Exploration of faculty perceptions of a new learning management system (Sakai) in an Irish university. Paper presented at the EdTech2006, Seventh Annual Irish Educational Technology Users' Conference, Sligo, Ireland, 25-26 May.

Roberts, G. (2005). Technology and learning expectations of the net generation. In D. G. Oblinger \& J. L. E. Oblinger (Eds.), Educating the net generation (pp. 3.1-3.7). EDUCAUSE.

Roschelle, J., Penuel, W. R., \& Abrahamson, L. A. (2004). The networked classroom. Educational Leadership, 61(5), 50-54.

Simpson, V., \& Oliver, M. (2007). Electronic voting system for lectures then and now: A comparison of research and practice. Australian Journal of Educational Technology, 23(2), 187-208.

Skiba, D., \& Barton, A. (2006). Adapting your teaching to accommodate the net generation of learners. OJIN: The Online Journal of Issues in Nursing, 11(2), 15. Retrieved from http://www.nursingworld.org/MainMenuCategories/ANAMarketplace/ANAPeriodicals/OJIN/Tableof Contents/Volume112006/No2May06/tpc30_416076.aspx

Stein, P., Challman, S. D., \& Brueckner, J. K. (2006). Using audience response technology for pretest reviews in an undergraduate nursing course. Journal of Nursing Education, 45(11), 469-473.

Trapskin, P. J., Smith, K. M., Armitstead, J. A., \& Davis, G.A. (2006). Use of an audience response system to introduce an anticoagulation guide to physicians, pharmacists, and pharmacy students. American Journal of Pharmaceutical Education, 69(Article 28).

Trotter, A. (2005). Technology turns test-prep into clicking experience. Education Week, 24(36), 8-9.

Weimer, M. (2002). Learner centered teaching: Five key changes to practice. San Francisco: Jossey-Bass. 


\section{Biographies}

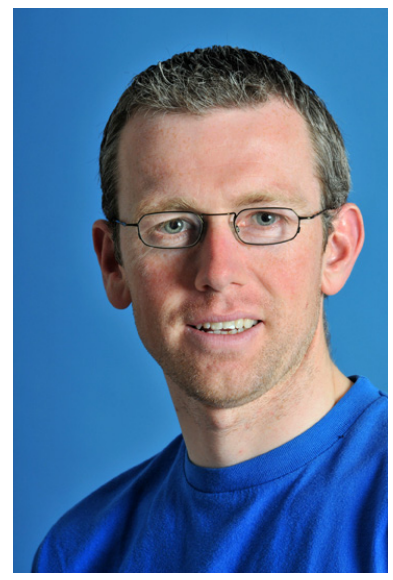

Dr. Kevin Johnson PhD, M.Eng, B.Eng. Kevin has a degree in Electronic Engineering and an MEng in Computer Engineering from the University of Limerick. He started as a PhD student in 2001 and graduated with a $\mathrm{PhD}$ in 2004 after working on the Encompass Project. To date he has worked on a number of projects within the Educational Media Research Centre. He worked to design two other tools for the Encompass project using LAMP (Linux, Apache, MySQL and PHP) technologies.

He has worked on the Consortium for Open Source in the Public Administration (COSPA) project, funded within the IST (Information Society Technologies) Priority of the EU's Sixth Framework Programme (FP6) and also on the IDEAs Project as a Sys Admin and Technical Consultant. He also teaches programming modules like Java, Java Advanced, Assembly Language and $\mathrm{C}++$ with the Department of Electronic and Computer Engineering.

In 2008, Kevin joined the Nursing and Midwifery department in the University of Limerick. He is a Senior Audio Visual Technician with a strong interest in e-learning and online teaching. He currently helps the staff to enhance their learning approach with their students via online and blended approaches as well as mobile interaction.

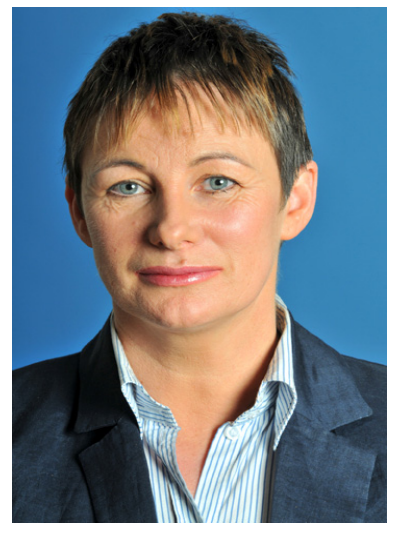

Ms Catherine Lillis, RGN, RM, MSc, LSHTM Post Grad Dip, Dip (Higher Ed), Health Planning \& Management, L.C.P.H. MCPH. Catherine is an experienced practitioner, and developed her clinical, management, research and teaching skills in a variety of professional environments nationally and internationally. Over the years, she has liaised with hospitals and organisations and where appropriate provided specialist advice and leadership. Catherine has particularly enjoyed the challenge of been a project leader with International Raleigh and organising and leading a Professional Skin Care Education Conference at Regents College, London in 2003.

From 2004, she have supervised and assessed BSc Final Year Research Projects, and the Graduate Diploma/MSc Programmes. She joined the Department of Nursing/Midwifery, University of Limerick, as a lecturer in 2007 and lectured across the BSc Pre-Registration Nursing/Midwifery Programmes and the Higher Diploma in Midwifery.

Her research interests include Environmental Health, Fetal Environment, Birth Environment, Perinatal Outcomes, Low and High Risk Pregnancy, Information Technology in Education, Skin Care, Holistic Care 